\title{
Letter from the Editor-in-Chief: JIBS status report - the first 18 months
}

\section{Lorraine Eden}

Journal of International Business Studies (2009) 40, 713-7/8. doi: 10.1057/jibs.2009.20
Volume 40.5 consists of eight papers, all of which were originally submitted to the former JIBS editorial team; most of these manuscripts were subsequently shifted to and accepted for publication under my watch. Rather than discuss the highlights of the papers in this issue (and apologies to the authors for my omission here), I want, instead, to provide the journal's stakeholders and the broader international business (IB) scholarly community with a status report on the journal. Since my editors and I are about half-way through our term (1 July 2007-31 December 2010), and the call for a new editorial team has been posted at http://aib.msu.edu, now it is an appropriate time to take stock of our accomplishments. This Editor-in-Chief (EIC) Letter therefore highlights JIBS performance statistics for the 18-month period July 2007-December 2008. Please see the JIBS website for past and upcoming activities, in particular, activities related to our 40th Anniversary in 2009.

\section{JIBS STATISTICS AT A GLANCE}

A good place to start is overview statistics for the journal from 2002 through 2008. As Table 1 shows, JIBS submissions grew from 214 manuscripts in 2002 to a peak of 589 manuscripts in 2006. Total submissions dropped to 494 in 2007 (the transition year between the old and new editorial teams), partly recovering to 514 last year. The number of published papers rose from 43 in 2002 to 76 in 2008; the number of issues rose from six to eight. The number of pages is perhaps the most remarkable change, rising from 835 pages in 2002 to 1391 pages in 2008.

It is well known that journal submissions are likely to decline during editorial transitions because authors prefer not to be caught between editorial teams. The situation was more complex for this transition due to two additional changes, first, shifting the JIBS web-based editorial management system from Outdare to Manuscript Central, and second, moving the JIBS office from the EIC's university to AIB Headquarters at Michigan State. These transitions may explain the 2007 submissions level, but the slow recovery in 2008 suggests other factors may also be important. A short-run reason may have been the backlog of accepted but not yet published manuscripts by the previous editors, as backlogs tend to discourage submissions. However, papers accepted for publication in JIBS are now quickly available in their final, citable version through the JIBS Advance Online Publication (AOP) system. ${ }^{1}$ Moreover, the growth in issues and pages in 2008, together the 
Table 1 JIBS statistics at a glance

\begin{tabular}{|c|c|c|c|c|c|c|c|}
\hline & 2002 & 2003 & 2004 & 2005 & 2006 & 2007 & 2008 \\
\hline \multicolumn{8}{|c|}{ Thomson web of Social Sciences Citation Index (SSCI) data } \\
\hline Total citations & 1653 & 1661 & 1884 & 1788 & 2554 & 3101 & NA \\
\hline SSCI journal impact factor & 1.460 & 1.393 & 1.286 & 1.250 & 2.254 & 2.283 & NA \\
\hline - Rank among business journals & 15 & 14 & 12 & 16 & 8 & 7 & NA \\
\hline - Rank among management journals & 14 & 18 & 16 & 23 & 8 & 10 & NA \\
\hline SSCI journal immediacy index & 0.023 & 0.146 & 0.581 & 0.125 & 0.173 & 0.348 & NA \\
\hline - Rank among business journals & 43 & 43 & 6 & 24 & 24 & 13 & NA \\
\hline - Rank among management journals & 15 & 14 & 12 & 32 & 36 & 18 & NA \\
\hline \multicolumn{8}{|l|}{ JIBS submission and publication statistics } \\
\hline Total submissions & 214 & 414 & 437 & 550 & 589 & 494 & 514 \\
\hline Published papers & 43 & 41 & 31 & 40 & 52 & 66 & 76 \\
\hline Number of issues & 6 & 6 & 6 & 6 & 7 & 8 & 8 \\
\hline Number of pages & 835 & 603 & 570 & 726 & 942 & 1244 & 1391 \\
\hline
\end{tabular}

growth in 2009 (JIBS will publish nine issues with up to 1640 pages), will eliminate the backlog this year.

Table 1 also includes Thomson's Social Sciences Citation Index (SSCI) data for 2002-2007. Total citations of JIBS papers, for journals that are included in SSCI, almost doubled over the period from 1653 to 3101 . The JIBS impact factor ${ }^{2}$ broke the "2.0" threshold (often seen as demarking an " $\mathrm{A}$ " or top-tier journal) in 2006, moving up from 1.46 in 2002 to 2.283 in 2007 (the most recent year available). In 2007, JIBS ranked seventh in the Business Journals and 10th in the Management Journals categories. We anticipate that total JIBS citations, as recorded by SSCI, should rise rapidly over the next few years as several IB journals (e.g., Management International Review, Journal of International Management) were added to the SSCI last year and their citations of JIBS papers will start to positively affect both JIBS citation counts and the JIBS impact factor. Lastly, the journal immediacy index, which shows on average how quickly JIBS papers are cited, has typically been less than 0.2 over the whole period (with the exception of 2004), but rose to 0.348 in $2007 .^{3}$ The AOP system has probably helped to (and will continue to) improve our journal immediacy index.

\section{JIBS SUBMISSION PROCESS STATISTICS}

Between July 2007 and December 2008, JIBS received 609 new unsolicited submissions (588 articles, 16 research notes and five perspectives). In addition, 200 new submissions were submitted in response to Calls for Papers for three Special
Issues ("Asia and IB": 73 submissions, "JIBS40th/ AIB50th Anniversary": 73, and "Conflict and IB": 54 ), for a total of 809 new submissions or original manuscripts (OMs). Sixty-three manuscripts were transferred from the old JIBS team during the transition to the new team. In total, my editorial team handled 872 manuscripts over its first 18 months, an average of 49 manuscripts per month.

The reviewing process at JIBS consists of three stages. At the first stage, the manuscripts go through an internal review process whereby they are read and assessed typically by three individuals, using minimum fit, quality and contribution guidelines developed by the editorial team (see Box 1 for details). The three "sets of eyes" are the JIBS Reviewing Editor, EIC and Area or Consulting Editor assigned to the file; manuscripts can be desk rejected by any one of these individuals. The decision to desk reject a manuscript is not taken lightly. We recognize that too low a desk rejection rate can have a chilling effect on reviewers who are given too many manuscripts to read that have no hope of being accepted for publication in JIBS; too high a desk rejection rate has a chilling effect on authors who are turned off from frequent desk rejections.

Although we do not keep statistics on why papers were desk rejected by the editorial team because typically more than one reason is involved, a frequent reason was "lack of fit"; that is, the subject matter did not fall within the JIBS domain statement (see the JIBS Statement of Editorial policy; a short summary is provided in Box 2). The first question asked by a JIBS editor when reading a new 


\section{Box 1 JIBS desk reject criteria}

Lack of fit

- The problem addressed in the manuscript does not fall within the domain of international business studies, as defined in the JIBS Statement of Editorial Policy.

- The JIBS editors' letter "What makes a study sufficiently international?" in JIBS may also be relevant and helpful as an explanation for lack of fit.

\section{Problems with quality}

- The manuscript does not have sufficient intellectual depth.

- The methods/analysis in the manuscript are not appropriate to the research question being asked or they do not appear to be reasonably rigorous.

- The manuscript does not conform to generally accepted standards of scholarship in terms of style, content and writing or the manuscript is excessively long.

Insufficient contribution to international business studies

- The research is unlikely to be sufficiently interesting to international business scholars.

- The manuscript does not sufficiently advance our knowledge of international business studies.

Editor's recommendation

- JIBS is not an appropriate journal for publication of this manuscript because ; a more appropriate journal would be

Option to revise and resubmit

- Your manuscript has the following problem(s), which would most likely to lead to rejection if the manuscript were sent out for external review. The problem appears to be fixable and you are therefore invited to revise the paper as a new submission to JIBS.

Box 2 The domain of international business studies

- the activities, strategies, structures and decision-making processes of multinational enterprises;

- interactions between multinational enterprises and other actors, organizations and institutions;

- the cross-border activities of firms (e.g., intrafirm trade, finance, investment, technology transfers, offshore services);

- how the international environment (e.g., cultural, political, economic) affects the activities, strategies, structures and decision-making processes of firms;

- comparative studies of businesses, business processes and organizational behavior in different countries and environments; and

- the international dimensions of organizational forms (e.g., strategic alliances, mergers and acquisitions) and activities (e.g., entrepreneurship, knowledge-based competition, corporate governance). submission is: Why JIBS? That is, why is JIBS an appropriate publication home for this manuscript? The editor should be able to see clearly why and how the manuscript fits within the JIBS domain statement, and why the paper would be of interest to JIBS readers. For example, a large subgroup of the "no fit" papers desk rejected over the 18-month period involved domestic firms engaged in domestic activities in a non-US country; this ethnocentric view of IB ("anything non-US is international") is not acceptable in JIBS, and in such cases, the authors are referred to the Letter from the Editors on "What makes a study sufficiently international?" in JIBS 39.2.

Over the 18-month period, 430 of the 809 OM submissions were sent for external review, which implies a desk rejection rate of $47 \%$, with the average time between submission and internal decision of 6 days. The desk rejection percentage, however, is misleading as perhaps $10-15 \%$ of the desk reject letters also receive an invitation to revise and resubmit. This happens in situations where the internal editor sees potentially fatal flaws that the authors should be able to fix before the external review process. Examples include situations where the author has not addressed the "why JIBS?" question; the international content of the manuscript is low; there are visible flaws in the empirical methods; the manuscript is excessively long; the contribution to the IB literature is not clear; or the paper is too narrowly focused for the broad JIBS readership. All of these are cases where authors may be able to relatively easily amend the manuscript, resubmit it and therefore reduce the probability of rejection after external review. As manuscripts that have been desk rejected through internal review can be revised and sent back as a new JIBS submission whereas manuscripts that have been rejected through external review cannot, we see the desk rejection process as benefiting both authors and reviewers. Even when the manuscript is not invited for resubmission, the editor typically provides detailed comments to the author together with suggestions for more appropriate journals.

At the second stage, manuscripts are sent out for external review by the Area or Consulting Editor handling the file. When the reviews are in, the editor reads the manuscript, reviews and recommendations, and writes a detailed, developmental decision letter. Of the $430 \mathrm{OM}$ submissions sent for external review, 131 received a revise-and-resubmit decision; 296 received a reject decision and three 
were withdrawn by the authors. Average turnaround time, from author submission to first decision, was 69 days (63 days from editor selection to first decision). Thus, of the 430 OMs, 30\% received a positive decision on the first round; that is, nearly one-third of OM submissions with decisions received a positive revise-and-resubmit decision within 2 months of manuscript submission. We view this statistic as evidence that our desk rejection process is successful; on average, one in three manuscripts that meet minimum JIBS fit, quality and contribution criteria receive an invitation to revise and resubmit after the first round of external review.

The third stage of the editorial process begins when authors send back their revised manuscripts to the Area or Consulting Editor for a second round of external reviews; this is the "Revision 1" (R1) stage. At the time of this letter, of the 131 invited resubmissions, 106 R1 manuscripts were submitted; 9 were withdrawn or expired; 16 submissions were pending and 13 had pending editorial decisions; that is, of the 131 invited OM resubmissions, 93 R1 manuscripts had received decisions. Of the $93 \mathrm{R} 1$ manuscripts with decisions, 29\% were rejected after review; $55 \%$ received revise-and-resubmit decisions and $16 \%$ received conditional acceptance and acceptance decisions; average time to decision was 62 days. In other words, $71 \%$ of $R 1$ manuscripts with decisions received a positive decision (that is, either revise and resubmit, conditional accept or accept) within 2 months.

At the "Revision 2" (R2) stage, when the authors send back a second revision, the results were even clearer and faster. Of R2 manuscripts with decisions, about 5\% were rejected after external review; $76 \%$ were accepted or conditionally accepted; and the remaining 19\% received revise-and-resubmit decisions - all within an average of 36 days. In other words, 95\% of R2 manuscripts with decisions received a positive decision within 1 month. A small number of manuscripts went on to Revision 3 (R3) or Revision 4 (R4) stages; all but one of these manuscripts, to date, have been accepted or conditionally accepted for publication; average time to decision about 20 days.

The total time between author submission and final decision is also an important component of the journal process, one that matters particularly to PhD students and untenured junior faculty. Looking at the "time to decision" statistics reported above, we estimate the total time inside the JIBS editorial system for new manuscripts submitted after July 2007 was an average of 187 days (6 months) from original submission to manuscript acceptance at the R3 stage. If we assume that authors take the full time allowed for manuscript revisions, we must also include 9 months for author revisions. ${ }^{4}$ Total time from $O M$ submission to $R 3$ acceptance is therefore 6 months in review with JIBS plus 9 months in revision with the authors, for a total time from first submission to journal acceptance averaging 15 months. If authors were to reduce their turnaround time to 1 month per revision, total time from OM submission to journal acceptance could be as low as 9 months.

Authors may also be interested in maximum turnaround times for each stage of the editorial process; that is, what is the longest expected time between author submission and an editorial decision? Our estimate is that $95 \%$ of all new submissions during our first 18 months received (a) a first round decision within 116 days of OM submission; (b) a second decision within 94 days of R1 submission; (c) a third decision within 85 days of R2 submission; and (d) a fourth decision within 23 days of R3 submission. Thus, the longest turnaround time for 95\% of manuscripts was 4 months; this occurred in the first round from submission to first decision.

We have been able to cut the time to decision by streamlining the process for reviewers, authors and editors. Looking first at reviewers, most are JIBS Editorial Review Board (ERB) and Consulting Editors Board (CEB) members who know that they are expected to complete reviews within 1 month. The JIBS Manuscript Central system tracks overdue reviews and sends automatic reminders until the reviews are received. Editors can make decisions with less than three reviews when necessary. (Manuscripts received three reviews $77 \%$ of the time and two reviews 23\% of the time.) Metrics on the number, quality and timeliness of reviews are generated regularly. These metrics are used by the editorial team to select the new annual JIBS Best Reviewer Awards, and are important factors in determining who receives (and does not receive) invitations to join the ERB and CEB. Second, authors are asked to submit their revised manuscripts within 4 months after receiving a revise-andresubmit invitation; once the paper receives a conditional acceptance, the time limit is shortened to 1 month. (Many authors however do request (and receive) extensions from JIBS Managing Editor Anne Hoekman, which lengthens the total time involved.) Lastly, in terms of the JIBS editors, Manuscript Central also tracks how long it takes for editors to write decision letters, and overdue letters also trigger reminders. My editorial team is 
continually looking for ways to shorten the time to decision while also raising the quality of the reviewing process.

\section{THE JIBS ACCEPTANCE RATE}

What does all of this imply for the JIBS acceptance rate? Journal acceptance rates are difficult to calculate. Simply comparing the number of submissions in 1 year to the number of papers published in the same year (for example, using the statistics in Table 1) is a not a good metric for an obvious reason. Submissions at one point in time are often not finalized (either ultimately rejected or accepted for publication) for up to 2 years after the original submission date because of the time it takes to revise manuscripts after each round of review.

If total number of published papers divided by total number of submissions is not an appropriate metric, how can one calculate the JIBS acceptance rate? One way to do this would be to look at original submissions over the 18-month period and calculate the percentage that moved to acceptance. Of the manuscripts with decisions, our estimate of a JIBS acceptance rate using this metric is $11 \%$. However, we must add an important caveat here: the acceptance rate will be overstated to the extent that manuscripts without decisions oversample on situations where authors are taking an above average time to revise and/or editors and reviewers to review, which in turn suggests manuscripts without decisions may be disproportionately likely to (a) be withdrawn or have their invitations to resubmit expire, and (b) be rejected. Thus, correcting for selection effects from leakages on the authors' side (delay in resubmissions, withdrawals) and on the journal's side (reviews and decisions pending), we believe the JIBS acceptance rate over the past 18 months has been approximately $10 \%$.

Although our acceptance rate is somewhat higher than anticipated (we expected the rate to be in the $7 \%$ range), the data are not available to compare our acceptance rate with the previous editorial team in order to determine whether the rate has risen or fallen. It is possible that the overall quality of papers being submitted to JIBS is rising, which may be partly due to our JIBS Paper Development Workshops and the editors' frequent participation in doctoral, junior faculty and meet the editor workshops. Our desk rejection system may also be positively affecting the overall acceptance rate. The current editorial team closely monitors the quality of papers accepted for the journal, and will make sure that appropriate quality standards are maintained at all times.
Box 3 JIBS special issues, July 2007-December 2010

- Asia and Global Business in the 21st Century: Institutions, Cultures and Strategic Transformations. Special Issue Editors: Sea-jin Chang, Rabi S. Bhagat, Mike W Peng. Submission deadline 1 December 2007.

- The JIBS 40th/AIB50th Anniversary Issue: Innovations in International Business Theory. Submission deadline 15 March 2008.

- Conflict, Security and Political Risk: International Business in Challenging Times Special Issue Editors: Witold Henisz, Edward D Mansfield and Mary Ann Von Glinow. Submission deadline 31 October 2008.

- Qualitative Research in International Business. Special Issue editors: Rosalie L Tung, Julian Birkinshaw and Mary Yoko Brannen. Submission deadline 15 September 2009.

- Global Economic Crises and International Business: Special Issue in Memory of John H Dunning. Special Issue Editors: Lemma W Senbet, Alain Verbeke, Arjen van Witteloostuijn, and Srilata A Zaheer. Submission deadline 29 January 2010.

\section{CONCLUSION: A "GOOD NEWS" STORY}

The "good news" my editors and I want to share with you in this EIC Letter is that JIBS now has in place a journal submission system that provides highquality and timely feedback on your journal submissions and the statistics to prove it. We believe that these statistics should encourage more and higher quality submissions to the journal as authors recognize the performance improvements in the journal submission process at JIBS. The JIBS editors welcome more submissions. We are looking for manuscripts that fit under the "umbrella" of the JIBS Statement of Editorial Policy and that make innovative and insightful contributions to IB studies.

In addition to regular submissions on any IB topic, we are also actively encouraging manuscripts through broad Calls for Papers around current themes in IB. The current list of Special Issues is provided in Box 3. I would like to draw your attention to two upcoming Calls for Papers and encourage your submissions: (1) Qualitative Research in International Business with Special Issue Editors Rosalie L Tung, Julian Birkinshaw and Mary Yoko Brannen (due date 15 September 2009); and (2) Global Economic Crises and International Business with Special Issue Editors Lemma W Senbet, Alain Verbeke, Arjen van Witteloostuijn and Srilata A Zaheer (due date 29 January 2010).

I conclude by asking: When has there been a better time to submit your manuscripts to JIBS?

\section{ACKNOWLEDGEMENTS}

The assistance and comments of Anne Hoekman, Witold Henisz, Alain Verbeke, Paul Beamish, Deanna 
Johnston, Alan Rugman and Anand Swaminathan are gratefully acknowledged. Please send your comments on this EIC Letter or on other issues related to JIBS to editor-in-chief@jibs.net.

\section{NOTES}

${ }^{1}$ As papers are accepted for publication, they are published on the JIBS website in the AOP system. See "How soon can you read and cite JIBS articles?" by David Bull, Director of Journals at Palgrave Macmillan, in the 1st Quarter 2008 AlB Newsletter at http:// aib.msu.edu/publications/.

${ }^{2}$ The journal impact factor is calculated as the ratio of the number of current citations of papers published in that journal in the previous two years to the total number of papers published in the journal in the previous two years.
${ }^{3}$ The journal immediacy index shows how quickly, on average, a paper is cited. The ratio is calculated as the number of citations in a given year of papers published in that year, divided by the number of papers published in that year. The higher is the number, the greater is the immediacy of impact.

${ }^{4}$ Average total time with the journal equals 187 days: 69 (from submission to first decision) +62 (from R1 submission to second decision) +36 (from R2 submission to third decision) +20 (from R3 submission to final decision). Total time with authors equals 9 months: 4 (from OM to R1) +4 (from R1 to R2) +1 (from R2 to R3 assuming that the R2 manuscript received a conditional accept or minor revisions decision). Very rarely a manuscript proceeds to the R4 stage, which lengthens the process by another 20 days internally and adds another month with the authors. 